\section{Overhanging Dental Restorations and Periodontal Disease}

\author{
by \\ Neville Gilmore,* L.D.S., D.M.D., M.P.H. \\ AubreY SHEIHAM,** B.D.S., PH.D.
}

It is generally accepted that inflammatory periodontal disease is caused by local irritation. In addition to dental plaque and calculus, overhanging margins to dental restorations have been cited as local irritants in periodontal disease. ${ }^{1-3}$ In a committee report from the World Workshop in Periodontics, ${ }^{4}$ it was stated that "overhanging restorations are local factors which initiate, enhance or supplement periodontal disease . . ." It would indeed be ironic if in the process of restoring teeth affected by dental caries, dentistry in any way contributed to the causation of periodontal disease, thereby threatening the longevity of the restored teeth.

Some studies have reported an association between overhanging dental restorations and periodontal disease; however, only the presence or absence of periodontal disease was reported. ${ }^{5,}{ }^{6}$ In view of the potential threat, it is surprising that no reports of studies on the amount of periodontal destruction related to overhanging restorations in humans were found in the available literature. One study found no correlation between periodontal disease and overhanging margins. In this study periodontal disease was assessed by the Periodontal Disease Index; $;$ the severity of the overhang was graded according to its relation to the gingival margin, with subgingival overhangs being graded more severely.

More recently, ${ }^{9}$ a highly significant reduction in alveolar bone height was reported relative to metal restorations with marginal excess equal to or greater than $0.2 \mathrm{~mm}$. A lesser, nonsignificant, reduction was related to marginal defects of less than $0.2 \mathrm{~mm}$. In this study, a method of projection of, and measurement from, dental radiographs was used to compare bone height adjacent to defective margins with that of the same surface of the contralateral tooth.

The study to be reported here was conducted to test the hypothesis that overhanging dental restorations in

\footnotetext{
The research project upon which this report is based and the analysis were supported in part by Public Health Service grants (D-681, 5 FO3 DH 38,602-02, and 5 TO1 DH 02005-02) from the National Institutes of Health.

* Associate Professor, Department of Social Dentistry, Tufts University School of Dental Medicine, Boston, Massachusetts.

**Visiting Assistant Professor of Dental Public Health and Community Dentistry, Schools of Public Health and Dentistry, The University of Michigan, Ann Arbor, Michigan; on leave from The London Hospital Medical College Dental School, Department of Oral Medicine, London, England.
}

posterior teeth were associated with more severe periodontal disease than similar teeth without overhanging restorations. In addition, the prevalence and distribution of overhanging posterior restorations (hereafter referred to as O.P.R.) was estimated.

\section{Materials AND Methods}

\section{Survey Population}

A considerable body of data, together with intraoral radiographs, was made available to the present investigators. The details of the methods and criteria used in the original survey have been published. ${ }^{10,11}$

The original investigators had attempted to secure a representative civilian sample of a New Mexican population aged 18 to 44 years. Sample quotas had been estimated and the field surveys had been conducted in a mobile dental unit throughout the state. Only persons with one or more natural teeth had been examined.

\section{The Clinical Examination}

The clinical examinations had been conducted by one examiner. The gingival and periodontal status had been assessed using the P.D.I. developed by Ramfjord, ${ }^{8}$ by whom the examiner had been instructed. Periodontal status was also assessed radiographically. ${ }^{10}$

\section{Radiographic Examination}

The radiographic examination had been carried out using a Ritter Model E radiographic unit with a long cone (cone distance 16 inches) and a right angle technique with Eastman Ultra-Speed DF 57, DF 55. Fifteen periapical and four bitewing intraoral films had been exposed for each subject.

For the present radiographic assessment a randomized selection of full mouth radiographs of the survey subjects was examined by one examiner and the alveolar bone height adjacent to each overhang and its homologue tooth surface was assessed in tenths of tooth length using a plastic ruler designed by Schei et al, ${ }^{12}$ and in millimeters with a standard ruler. The Schei ruler was placed, with the narrow end anteriorly, so that the scored lines representing zero and ten tenths were tangential to the most occlusal extent of the crown, and the most apical extent of the root, respectively. The height of the crown coronal to the alveolar crest immediately adjacent to each overhang and its homologue was recorded to the nearest tenth using the periapical radiographs. The same interval, bone crest to crown tip, was measured in millimeters using the bitewing radiographs and a plastic millimeter ruler. It was necessary to modify the method of Schei et al because many of the cementoenamel junctions, reference points used by Schei, were obscured by restorative material. 


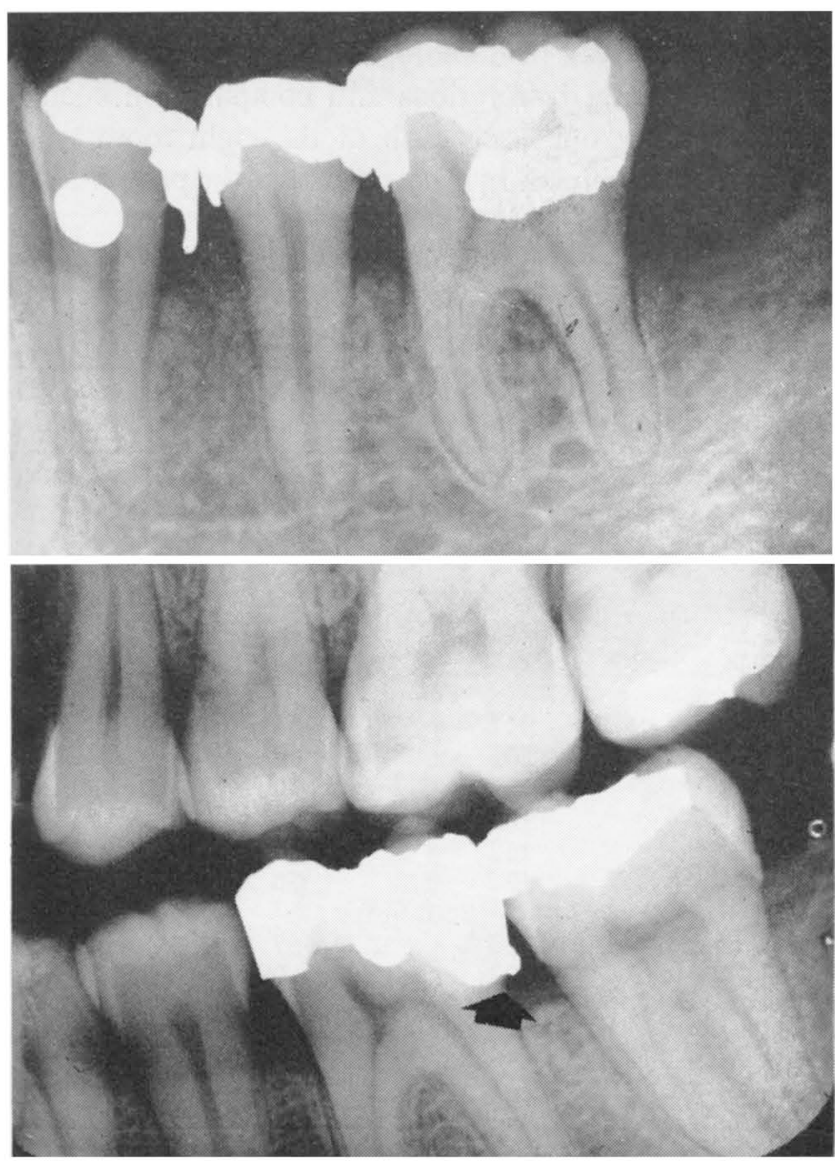

FIGURE 1. Illustration of restorations which were considered to have overhangs. Above: All four of the proximally restored surfaces were considered as overhangs. Below: Only the distal surface of the lower first molar was considered to have an overhang.

The difference, in tenths of tooth length and in millimeters, between overhang and homologue surfaces was determined for each mouth. Where more than one overhang was present in a mouth, a mean difference was computed for the number of pairs of overhang and homologous surfaces evaluated. No measurements were made when both homologous surfaces had an overhanging restoration. In each mouth only the premolars and first and second molars were evaluated. Alternate batches of approximately 175 sets of radiographs were examined for the presence of O.P.R. by each examiner, who thereby diagnosed about half of the material.

\section{Criteria for Overhanging Proximal Restorations}

A proximal restoration was considered to have an overhang when there was a distinct ledge of radiopaque filling material, which did not conform to the interproximal contour of the tooth, visible interproximally on the radiographs. Examples of what was considered an overhanging restoration are shown in Figure 1. To improve inter- and intraexaminer reproducibility, only distinct ledges were included as overhangs. Therefore, the prevalence figures quoted in this paper underestimate the true prevalence of overhanging restorations. No attempt was made to distinguish between gold and amalgam restorations.

\section{Examiner Reproducibility}

The present examiners diagnosed the overhanging restorations. After initial calibration, each examiner examined a random selection of sets of radiographs twice, six weeks apart. In addition, at the second examination, examiner 2 examined those sets examined by examiner 1 . Although differences existed within and between examiners, the magnitude of the differences was sufficiently small that they were considered unlikely to affect the outcome of the study.

\section{Statistical Analyses}

For each pair of overhang and homologue tooth surfaces, differences in gingivitis (P.D.I. 0-3) and periodontal disease (P.D.I. 5 and above) were recorded together with the direction of the difference. The Wilcoxon matched pairs signed ranks test ${ }^{13}$ (" $T$ " value) was employed to test the significance of any observed differences in P.D.I. scores. For actual measurements, in tenths of tooth length and in millimeters, differences between overhang and homologue subjects were tested with the Student "t" test.

\section{RESUlTS}

Radiographs had not been taken of persons who were either pregnant or had had any radiographic examination within the six months prior to the survey. Some radiographs were not suitable for the study. Of the 1,976 persons who had been examined, suitable sets of radiographs were obtained in 1,763 .

Thirty-two percent of the 1,763 persons who had been radiographically examined had one or more overhanging posterior dental restorations in their mouths; 25 percent of males and 38 percent of females (Table 1). Since this group included subjects with and without posterior proximal restorations, the data were analyzed to determine the average number of posterior teeth per mouth with proximal dental restorations (Table 2) and the percentage of posterior teeth with proximal restorations which had overhangs (Table 3 ). The average number of posterior teeth and posterior tooth surfaces per mouth which had proximal restorations increased with age from 1.53 and 2.00 at 18 to 24 years to 2.91 and 3.79 at 40 to 44 years, respectively (Table 2 ). In 18 to 24 year olds, 24 percent of teeth with proximal restorations and 20 percent of proximally restored surfaces had overhangs. Persons aged 40 to 44 years had 32 percent of restored teeth and 27 percent of restored proximal surfaces with overhangs (Table 3 ). It appears, therefore, that the increase in prevalence of O.P.R. with 
age was due in part to increases in the number of teeth and surfaces with restorations, with increasing age.

The differences in prevalence of overhangs between males and females as shown in Table 1 was not apparent when the data were analyzed by restored teeth and restored surfaces (Table 3 ). This showed that males and females had essentially similar percentages of O.P.R. teeth and surfaces.

The O.P.R. were not evenly distributed in the mouth. A higher percentage of O.P.R. occurred in the maxillary than in the mandibular quadrants. However, there was almost an equal distribution of O.P.R. on the right and left sides of each arch (Table 4). Although the overall distribution of O.P.R. indicated that the mesial and distal surfaces were approximately equally affected, certain teeth displayed a tendency for one surface to be affected more than the other. For example, mesial O.P.R. in maxillary first molars accounted for approximately 14 percent of all O.P.R. compared to approximately six percent by the distal surfaces of the same tooth (Table 5 ) ; distal of mandibular first premolars contributed 3.1 percent to total O.P.R. as opposed to 0.4 percent by mesial surfaces of the same tooth type.

\section{OVERHANGING RESTORATIONS AND Periodontal Disease}

Comparison of P.D.I. scores was possible in 456 subjects.

\section{Gingivitis}

Differences existed in 257 subjects; 136 in the predicted direction of the O.P.R. score being higher than the homologue. Actual "T" values (Wilcoxon) were not significantly different from those expected under a null hypothesis of gingivitis being unrelated to the presence of an overhang $(P=.20)$.

\section{Destructive Periodontal Disease}

Of the 456 possible comparisons, differences in P.D.I. scores between O.P.R. and homologue surfaces existed in 182 subjects; 114 in the predicted direction of the O.P.R. score's being higher. Actual "T" values (Wilcoxon) were significantly different $(P<0.001)$.

The test indicates a definite association of higher P.D.I. scores; i.e., more severe periodontal disease, with the presence of overhanging restorations.

Since restorations were present in all the affected teeth but not in all the nonaffected homologue teeth, the difference in P.D.I. scores may have been due to the higher prevalence of restorations in the O.P.R. than in the homologue teeth and the higher P.D.I. may be related to the presence of a dental restoration per se. To examine this possibility, the severity of periodontal disease was assessed in homologue teeth with and without proximal dental restorations and compared in each of the five age groups, for each of the eight tooth types, both sides combined. In each subgroup, the proportion of

TABLE 1

Prevalence of Persons with Overhanging Posterior Restorations in New Mexico by Age and Sex

\begin{tabular}{|c|c|c|c|}
\hline Age Groups & $\begin{array}{c}\text { Number of } \\
\text { Persons }\end{array}$ & $\begin{array}{c}\text { Persons with } \\
\text { Overhangs }\end{array}$ & $\begin{array}{c}\text { Percent with } \\
\text { Overhangs }\end{array}$ \\
\hline \multicolumn{4}{|c|}{ Males } \\
\hline All ages & 852 & 211 & 24.8 \\
\hline $18-24$ & 208 & 30 & 14.4 \\
\hline $25-29$ & 179 & 40 & 22.4 \\
\hline $30-34$ & 183 & 57 & 31.2 \\
\hline $35-39$ & 168 & 42 & 25.0 \\
\hline $40-44$ & 114 & 42 & 36.8 \\
\hline \multicolumn{4}{|c|}{ Females } \\
\hline All ages & 911 & 346 & 38.0 \\
\hline $18-24$ & 265 & 60 & 22.6 \\
\hline $25-29$ & 192 & 75 & 39.1 \\
\hline $30-34$ & 181 & 86 & 47.5 \\
\hline $35-39$ & 152 & 67 & 44.1 \\
\hline $40-44$ & 121 & 58 & 47.9 \\
\hline \multicolumn{4}{|c|}{ Both Sexes } \\
\hline All ages & 1763 & 557 & 31.6 \\
\hline $18-24$ & 473 & 90 & 19.0 \\
\hline $25-29$ & 371 & 115 & 31.0 \\
\hline $30-34$ & 364 & 143 & 39.3 \\
\hline $35-39$ & 320 & 109 & 34.1 \\
\hline $40-44$ & 235 & 100 & 42.6 \\
\hline
\end{tabular}

TABLE 2

Average Number of Posterior Teeth and Proximal Tooth Surfaces Restored per Mouth by Age

\begin{tabular}{|c|c|c|c|c|}
\hline $\begin{array}{c}\text { Age } \\
\text { Groups }\end{array}$ & $\begin{array}{l}\text { Average } \\
\text { Number } \\
\text { Posterior } \\
\text { Teeth } \\
\text { per } \\
\text { Person* }\end{array}$ & $\begin{array}{c}\text { Percent of } \\
\text { Posterior } \\
\text { Teeth } \\
\text { Proximally } \\
\text { Restored }\end{array}$ & $\begin{array}{c}\text { Average } \\
\text { Number of } \\
\text { Posterior } \\
\text { Teeth } \\
\text { Proximally } \\
\text { Restored } \\
\text { per Mouth }\end{array}$ & $\begin{array}{c}\text { Average } \\
\text { Number of } \\
\text { Surfaces } \\
\text { Proximally } \\
\text { Restored } \\
\text { per Mouth }\end{array}$ \\
\hline All ages & 14.0 & 16.8 & 2.35 & 3.10 \\
\hline $18-24$ & 14.9 & 10.3 & 1.53 & 2.00 \\
\hline $25-29$ & 14.3 & 15.8 & 2.26 & 2.90 \\
\hline $30-34$ & 13.9 & 20.9 & 2.90 & 3.98 \\
\hline $35-39$ & 13.4 & 19.7 & 2.63 & 3.47 \\
\hline $40-44$ & 12.7 & 23.0 & 2.91 & 3.79 \\
\hline
\end{tabular}

*Maximum possible $=16$ teeth.

TABLE 3

Prevalence of Overhangs in Posterior Teeth with Proximal Restorations, and in Restored Posterior Proximal Surfaces, by Age and Sex

\begin{tabular}{lllllll}
\hline & \multicolumn{6}{c}{ Percent with Overhangs } \\
\cline { 2 - 7 } & $18-24$ & $25-29$ & $30-34$ & $35-39$ & $40-44$ & All ages \\
\hline Restored Teeth & & & & & & \\
$\quad$ Males & 23.7 & 21.0 & 27.3 & 33.7 & 36.3 & 28.4 \\
$\quad$ Females & 24.3 & 29.6 & 29.7 & 33.5 & 30.0 & 29.5 \\
$\quad$ Both sexes & 24.1 & 26.5 & 28.8 & 33.6 & 32.3 & 29.1 \\
Restored Surfaces & & & & & & \\
$\quad$ Males & 21.5 & 18.3 & 20.6 & 30.7 & 29.6 & 23.9 \\
$\quad$ Females & 19.5 & 24.9 & 23.5 & 27.4 & 24.9 & 24.0 \\
$\quad$ Both sexes & 20.0 & 22.6 & 22.4 & 28.4 & 26.6 & 23.9 \\
\hline
\end{tabular}


TABle 4

Percentage Distribution of 1,308 Overhanging Posterior Restorations by Tooth Type and Mouth Quadrant

\begin{tabular}{lccccc}
\hline & $\begin{array}{c}\text { First } \\
\text { Premolar }\end{array}$ & $\begin{array}{c}\text { Second } \\
\text { Premolar }\end{array}$ & $\begin{array}{c}\text { First } \\
\text { Molar }\end{array}$ & $\begin{array}{c}\text { Second } \\
\text { Molar }\end{array}$ & Quadrant \\
\hline Maxilla & & & & & \\
$\quad$ Right side & 5.4 & 7.9 & 9.9 & 3.7 & 26.9 \\
$\quad \begin{array}{l}\text { Left side } \\
\text { Mandible }\end{array}$ & 7.2 & 11.0 & 10.9 & 4.7 & 33.8 \\
$\quad$ Right side & 1.6 & 5.1 & 9.6 & 3.1 & 19.4 \\
$\quad$ Left side & 1.8 & 5.4 & 9.1 & 3.7 & 20.0 \\
\hline
\end{tabular}

TABLE 5

Percentage Distribution of Overhanging Posterior Restorations by Tooth Type and Surface

\begin{tabular}{lccccc}
\hline & $\begin{array}{c}\text { First } \\
\text { Premolar }\end{array}$ & $\begin{array}{c}\text { Second } \\
\text { Premolar }\end{array}$ & $\begin{array}{c}\text { First } \\
\text { Molar }\end{array}$ & $\begin{array}{c}\text { Second } \\
\text { Molar }\end{array}$ & Quadrant \\
\hline Maxilla & & & & & \\
$\quad$ Mesial Right & 1.5 & 3.9 & 7.0 & 2.5 & 14.9 \\
Mesial Left & 2.8 & 4.8 & 7.3 & 3.1 & 18.0 \\
Distal Right & 3.9 & 4.0 & 2.9 & 1.1 & 11.9 \\
$\quad$ Distal Left & 4.4 & 6.2 & 3.6 & 1.6 & 15.8 \\
Mandible & & & & & \\
$\quad$ Mesial Right & 0.2 & 1.3 & 5.5 & 2.1 & 9.1 \\
Mesial Left & 0.2 & 1.0 & 4.7 & 3.0 & 8.9 \\
Distal Right & 1.4 & 3.8 & 4.0 & 1.1 & 10.3 \\
Distal Left & 1.7 & 4.3 & 4.4 & 0.6 & 11.0 \\
\hline
\end{tabular}

TABLE 6

Average Differences in Alveolar Bone Height, in Tenths of Tooth Length and Millimeters, Adjacent to Overhang and Homologue Tooth Surfaces, by Age Group

\begin{tabular}{lcccccc}
\hline & $18-24$ & $25-29$ & $30-34$ & $35-39$ & $40-44$ & $\begin{array}{c}\text { All ages } \pm \\
\text { Standard } \\
\text { Error }\end{array}$ \\
\hline $\begin{array}{l}\text { Tenths of } \\
\text { tooth length }\end{array}$ & .10 & .09 & .18 & .09 & .00 & $.08 \pm .035$ \\
$\begin{array}{l}\text { Number of } \\
\text { persons }\end{array}$ & 24 & 41 & 35 & 40 & 36 & 176 \\
$\begin{array}{l}\text { Millimeters } \\
\begin{array}{l}\text { Number of } \\
\text { persons }\end{array}\end{array}$ & .04 & .29 & .14 & .29 & .25 & $.22 \pm .061$ \\
\hline
\end{tabular}

Note: Differences represent a more apical bone level adjacent to tooth surfaces with overhanging restorations.

teeth with a P.D.I. score of 5 or greater was computed. Of the 40 subgroups, the proportion of restored teeth with a P.D.I. score of 5 or greater was higher than nonrestored teeth in 15 cells, lower in 16, with 6 tied and in 3 cells there were either no restored or no nonrestored teeth. From this finding it was concluded that a higher P.D.I. score was independent of the presence or absence of a proximal restoration, without an overhang.

Thus, the difference in P.D.I. scores between O.P.R. and homologue teeth is regarded as related to the presence of an overhang.

From the 970 sets of radiographs assigned to him, examiner 1 diagnosed at least one O.P.R. in each of 315 subjects. Differences in alveolar bone height, between O.P.R. and homologue teeth, could be computed from measurements in 208 of these subjects, in whom at least one pair of such teeth was present (Table 6).

The P.D.I. assesses the relationship between the base of the gingival crevice or pocket and the cementoenamel junction. Since there was a difference in P.D.I. scores between affected and nonaffected teeth, it was not surprising that persons with an O.P.R. were found to have an average of 0.22 millimeters or 0.08 tenths of tooth length less alveolar bone on the average adjacent to surfaces with O.P.R. than homologue surfaces without O.P.R. in the same mouth. Teeth with an O.P.R. had significantly more alveolar bone loss adjacent to the affected surface compared to the homologue surface when measured in millimeters of bone loss $(\mathrm{P}<0.001)$. Using tenths of tooth length as a measure of bone loss, the differences between affected and nonaffected teeth were also significant $(\mathrm{P}<0.02)$.

\section{Discussion}

A significantly greater severity of adjacent periodontal disease was found associated with overhanging posterior restorations than adjacent to homologue tooth surfaces. This finding and the high percentage of posterior restorations which had overhangs indicates that overhanging dental restorations are important local factors contributing to the severity of periodontal disease in human population groups.

It has been frequently stated that overhanging restorations cause gingivitis. ${ }^{1-5}$ Although the present study did demonstrate a greater severity of gingivitis adjacent to teeth with overhangs, the difference was not statistically significant. The reason for the nonsignificant difference may be that a large percentage of overhangs may not have been in direct contact with the gingiva and therefore nonirritating. The position of the overhang in relation to the gingiva had not been recorded. However, the same criticism can be directed at other studies of the relationship of gingivitis and overhangs which have shown a significantly greater severity of gingivitis adjacent to overhanging restorations.

It is interesting to note that Björn et $\mathrm{al},{ }^{9}$ in their study, found significant loss of alveolar bone only in relation to relatively severe overhangs and not to smaller overhangs. In view of the fact that in the present study only restorations with quite definite overhangs were scored, it is possible that only relatively marked overhangs are associated with periodontal disease because they favor plaque accumulation.

Although there was a statistically significant lower alveolar bone level adjacent to overhangs than adjacent to homologue surfaces, the differences were less than expected. This small difference may have been due to defects in the methods of measuring bone height and 
tooth length. However, when the ratio of average difference in bone heights by the "tenths of tooth length" and the "millimeter" method was used to estimate the average tooth length, the length computed $(27.1 \mathrm{~mm})$ does not differ markedly from the average tooth length figure of $24.4 \mathrm{~mm}$ for the same teeth used in the present study, as reported by Black (1902).$^{14}$ The similarity of these estimations indicates that the tenths and millimeter methods are equivocal and that the method of measurements used in this study did not underestimate alveolar bone height.

\section{SUMMARY AND CONCLUSIONS}

A study of data and radiographs from 1,976 New Mexicans aged 18 to 44 years was conducted to determine the relationship between overhanging posterior restorations and the severity of periodontal disease. Periodontal disease severity had been assessed using Ramfjord's method and by radiographic assessment. As radiographs had not been taken of all the survey population, the analysis was based on 1,763 subjects who had suitable radiographs.

1. Thirty-two percent of all persons, 25 percent of males and 38 percent of females, had one or more overhanging posterior restorations (Table 1).

2. One third of all posterior teeth with proximal dental restorations and one quarter of all restored proximal surfaces had overhangs (Table 3 ).

3. There was a significantly greater severity of destructive periodontal disease associated with posterior restorations with definite overhangs than in homologue teeth without such overhangs; the difference in severity of gingivitis around affected and nonaffected surfaces was not significant.

4. Persons with one or more overhanging posterior restorations had on average $0.22 \mathrm{~mm}$ less alveolar supporting bone adjacent to the surfaces with overhangs than adjacent to the homologue surfaces without overhangs.

It was concluded that posterior dental restorations with definite overhangs were positively related to the severity of periodontal disease in the study population.

\section{REFERENCES}

1. Goldman, H. M. and Cohen, D. W.: Periodontia; the Art and Science of Examination and Diagnosis of Periodontal Diseases, ed. 4. St. Louis, Mosby, 1957, 535 p. (p. 282-3).

2. Glickman, Irving: Clinical Periodontology; Recognition, Diagnosis, and Treatment of Periodontal Disease in the Practice of General Dentistry, ed. 3. Philadelphia, Saunders, 1964 , XIII + 902 p. (p. 315).

3. Stahl, S. S.: The Etiology of Periodontal DiseaseReview of Literature, p. 129-66. (In Ramfjord, S. P., Kerr, D. A. and Ash, M. M., eds. World Workshop in Periodontics, Ann Arbor, Michigan, June 6-9, 1966. Ann Arbor, University of Michigan c1966. XX +458 p.)

4. Committee Report-The Etiology of Periodontal Disease, p. 170. (In Ramfjord, S. P., Kerr, D. A. and Ash, M. M., eds. World Workshop in Periodontics, Ann Arbor, Michigan, June 6-9, 1966. Ann Arbor, University of Michigan, c1966. XX + 458 p.)

5. Wright, W. H.: Local Factors in Periodontal Disease. Dallas, Texas, Baylor University, College Dentistry, 1963, VII +77 p. Thesis.

6. Alexander, A. G.: Periodontal Aspects of Conservative Dentistry. Brit. Dent. J., 125:111-4, Aug. 6, 1968.

7. Knowles, J. W.: Occlusal Interferences and Periodontal Disease. Ann Arbor, University of Michigan, School Dentistry, 1966, IV + 68 p. Thesis.

8. Ramfjord, S. P.: Indices for Prevalence and Incidence of Periodontal Disease. J. Periodont., 30:51-9, Jan. 1959.

9. Björn, Anna-Lisa, Björn, H. and Grkovic, B.: Marginal Fit of Restorations and Its Relation to Periodontal Bone Level. Part I: Metal Fillings. Odont. Revy, 20-311-21, 1969.

10. Guyer, M. E. and Striffler, D. F.: The Reported Frequency of Toothbrushing as Related to the Prevalence of Periodontal Disease in New Mexico. J. Pub. Health Dent., 24:62-75, Summer 1964.

11. Sheiham, Aubrey and Striffler, D. F.: A Comparison of Four Epidemiological Methods of Assessing Periodontal Disease: A Study Conducted on a New Mexican Population. J. Periodont. Res. In press.

12. Schei, O., Waerhaug, J., Lovdal, A. and Arno, A.: Alveolar Bone Loss as Related to Oral Hygiene and Age. J. Periodont., 30:7-16, Jan. 1959.

13. Siegel, Sidney: Nonparametric Statistics for the Behavioral Sciences. New York, McGraw-Hill, 1956, XVII + 312 p. (p. 75).

14. Black, G. V.: Descriptive Anatomy of the Human Teeth, ed. 5. Philadelphia, S. S. White Dental Manufacturing Company, 1902, XVII + 169 p. (p. 16, 17).

\section{ACKNOWLEDGMENTS}

The authors would like to thank Dr. D. F. Striffler for his interest and encouragement in this work and for having made available to them the data and radiographs from the New Mexico survey. 